\title{
UM NOVO OLHAR SOBRE AS ALEGORIAS CARNAVALESCAS OS CARROS DE MUTAÇÃO DE ACARY MARGARIDA
}

Fabiana Machado Didoné

As alegorias carnavalescas estão incluídas no contexto dos objetos que foram categorizados como populares, decorativos, artesanais, exagerados e fantasiosos pela escrita da história da arte. Neste artigo, será abordada a produção artística de Acary Margarida voltada para o carnaval, com a criação e execução de carros de alegoria e mutação, permitindo, assim, lançar novo olhar sobre o lugar ocupado por esses objetos.

ALEGORIAS CARNAVALESCAS, CARROS DE MUTAÇÃO, ACARY MARGARIDA.

DIDONÉ, Fabiana Machado. Um novo olhar sobre as alegorias carnavalescas: os carros de mutação de Acary Margarida. Textos escolhidos de cultura $e$ arte populares, Rio de Janeiro, v.9, n.1, p. 143152, mai. 2012. 


\section{A NEW LOOK OVER CARNIVAL ALLEGORIES}

THE CHANGING FLOATS OF ACARY MARGARIDA

Fabiana Machado Didoné

Carnival floats are included in the context of objects that have been categorized as popular, decorative, handmade, exaggerated and fantasy-related in the writing of art history. In this article we will look at the artistic production of Acary Margarida aimed at carnival, with the creation and execution of allegory and changing floats, thus allowing the launch of a new look at the place occupied by these objects.

CARNIVAL ALLEGORIES, CHANGING FLOATS, ACARY MARGARIDA.

DIDONÉ, Fabiana Machado. Um novo olhar sobre as alegorias carnavalescas: os carros de mutação de Acary Margarida. Textos escolhidos de cultura $e$ arte populares, Rio de Janeiro, v.9, n.1, p. 143152, mai. 2012. 
Aborda-se aqui a produção de um artista que, além de sua escolha mais tradicional em pintura de retratos e paisagens seguindo os cânones acadêmicos, criou e executou, durante muitos anos, carros de alegoria e de mutação para o carnaval. Essas alegorias carnavalescas podem ser estudadas no contexto dos objetos categorizados como artesanais, decorativos, populares, fantasiosos e exagerados pela escrita da história da arte. Refletindo a respeito, lança-se o olhar sobre a rigidez das fronteiras da arte e sobre o lugar ocupado por esses objetos, definidos conforme sua qualidade artística.

Quando um objeto subverte um padrão estético predominante, seja por sua dimensão, sua conformação ou seu material fora do comum, ele enfrenta dificuldades de se contextualizar e de se fixar em determinados territórios. Só certos tipos de objetos têm a permissão para adentrar pelas portas das instituições de memória e de arte: os museus (MALTA, 2010, p.650).

A noção de obra de arte vem sofrendo diversas alterações ao longo de toda a história da arte, sendo o objeto artístico alvo de julgamentos que o definem como adequado ou não para ser considerado arte. Porém, à medida que se ampliam o diálogo e a interação entre os vários campos de saber, favorecendo o cruzamento e a diluição de conceitos, resultam novas perspectivas para o estudo dos objetos artísticos. Luciano Vinhosa ${ }^{1}$ (2011) traz à tona a inquietante questão 'o que é uma obra de arte hoje' e reflete acerca da noção de obra de arte caracterizada como mutante e obediente à dinâmica interna de uma prática. Segundo o autor, se a obra de arte for definida pela prática artística e a arte considerada um fazer e não uma teoria, "podemos reunir campos profissionais muitos distintos e autônomos entre si como o carnaval, a arte contemporânea, a moda, a arte popular, entre outros" (p. 2). Porém, essas práticas, distintas entre si, são identificadas com a arte em geral e se aproximam pela intenção estética. "Cada uma dessas artes, inscreve-se, no entanto, em campos profissionais específicos em atenção a suas regras, seus valores, seus circuitos, aos lugares de visibilidade e formas de produzir muito distintas" (p. 2). Uma definição de obra de arte, para o autor, deve ser considerada então, a partir do ponto de vista de um campo específico, ou seja, a partir do campo em que o objeto artístico em questão está situado.

O campo de produção artística voltada para o carnaval, com suas regras e valores específicos, é caracterizado pela subjetividade, pessoalidade e pelo forte apelo popular e sentimental. Os objetos artísticos produzidos para o carnaval, primam pela manufatura cuidadosa, pela exuberância das formas, pela 
combinação do uso de materiais nobres e ordinários e pela coerência com a temática estabelecida.

O artista plástico catarinense Acary Margarida (12.11.1907-11.1.1981) era um grande admirador de sua cidade, Florianópolis. Vindo de uma família de artistas, ${ }^{2}$ recebeu noções de desenho e pintura de seu pai, Joaquim Margarida, e continuou sua trajetória como autodidata. Iniciou-se na pintura aos oito anos de idade, e durante mais de 50 anos sua vasta produção plástica aconteceu, principalmente, no campo pictórico. Pintou cenas bíblicas e históricas, porém especializou-se em retratos e paisagens. Nos retratos, revelava, em traços firmes e expressivos, pessoas influentes da cidade e, também, personagens míticos. Nas paisagens, promovia as belezas naturais da Ilha de Santa Catarina e de outras cidades do interior do estado. Realizou inúmeras exposições e recebeu prêmios da Associação Paulista de Belas Artes. Manteve-se fiel ao estilo pictórico tradicional e acadêmico, apesar da chegada do modernismo em Florianópolis na década de 1940, o que contribuiu para que fosse, pouco a pouco, afastado do circuito de arte da cidade. Marginalizado, passou a ser visto como pintor popular até ser praticamente esquecido pela história artística da cidade, mantendo-se vivo apenas na memória de alguns antigos moradores.

Em paralelo à produção pictórica, desenvolveu, durantes vários anos seguidos, trabalho artístico voltado para o carnaval de Florianópolis. Foi responsável pela criação, elaboração e montagem de carros alegóricos e de mutação para diversas sociedades carnavalescas da época. Elaborou, também, a ornamentação dos salões de baile de carnaval dos principais clubes da cidade, conforme consta em nota veiculada em jornal da época sobre os preparativos para o carnaval no Lira Tênis Clube, tradicional clube da cidade: "e a majestosa ornamentação que está sendo feita em seus salões pelo artista Acary Margarida". ${ }^{3}$

O carnaval da Ilha sempre teve como apoio algum artista plástico que soube emprestar sua arte aos festejos do Momo. A família Margarida, por exemplo, já no século XIX, dava o toque de arte na província através do fotógrafo e artista plástico Joaquim Margarida [pai de Acary], mais tarde através do Acary [Margarida] (RAMOS, 1997, p.111).

As sociedades carnavalescas surgiram em Nossa Senhora do Desterro (atual Florianópolis) no século XIX, apoiadas pela imprensa e pelas autoridades, com o intuito de substituir o entrudo, brincadeira polêmica que consistia em jogar água e outros líquidos uns nos outros. Segundo Colaço (1998), eram entidades com fins de divertimento, porém iam além, participando de 


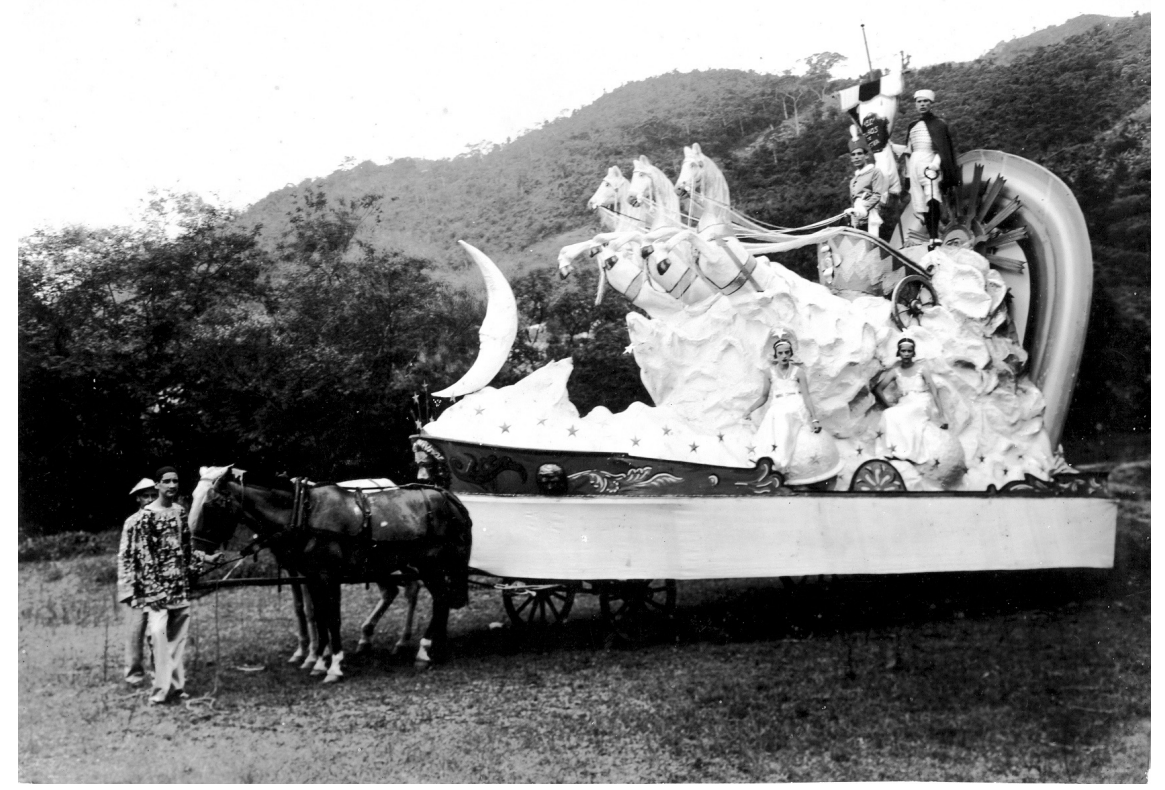

Figura 1: Antigo carro de alegoria e mutação da Sociedade Carnavalesca Filhos da Minerva, início do século XX Fonte: acervo fotográfico Casa da Memória

movimentos ideológicos, sociais e filantrópicos, como a causa abolicionista. No período de 1858 a 1899, havia 34 sociedades carnavalescas em Desterro.

No início do século XX, o carnaval de Florianópolis era animado pelos desfiles de préstitos e pelos carros de mutação das sociedades carnavalescas. Após os desfiles das grandes sociedades, os clubes locais realizavam bailes de máscaras e à fantasia para seus associados e convidados ao redor da Praça XV, a principal da cidade, previamente decorados com os mais variados temas, pelos artistas da cidade.

As grandes sociedades carnavalescas realizaram, durante muitas décadas, os desfiles de carros de alegoria e de mutação para o público. As sociedades carnavalescas diferiam das escolas de samba, pois desfilavam apenas com carros alegóricos, sendo que alguns eram construídos com mecanismos que proporcionavam "mutações", durante a apresentação (Figura 1). Os carros eram elaborados, durante meses, de acordo com o enredo e o tema individualmente escolhido pelas sociedades. Os desfiles eram divididos em dois concursos oficiais, mutação e alegoria. O regulamento previa a apresentação de no mínimo quatro e no máximo seis carros por sociedade, com destaque para o abre-alas e o carro da rainha. 


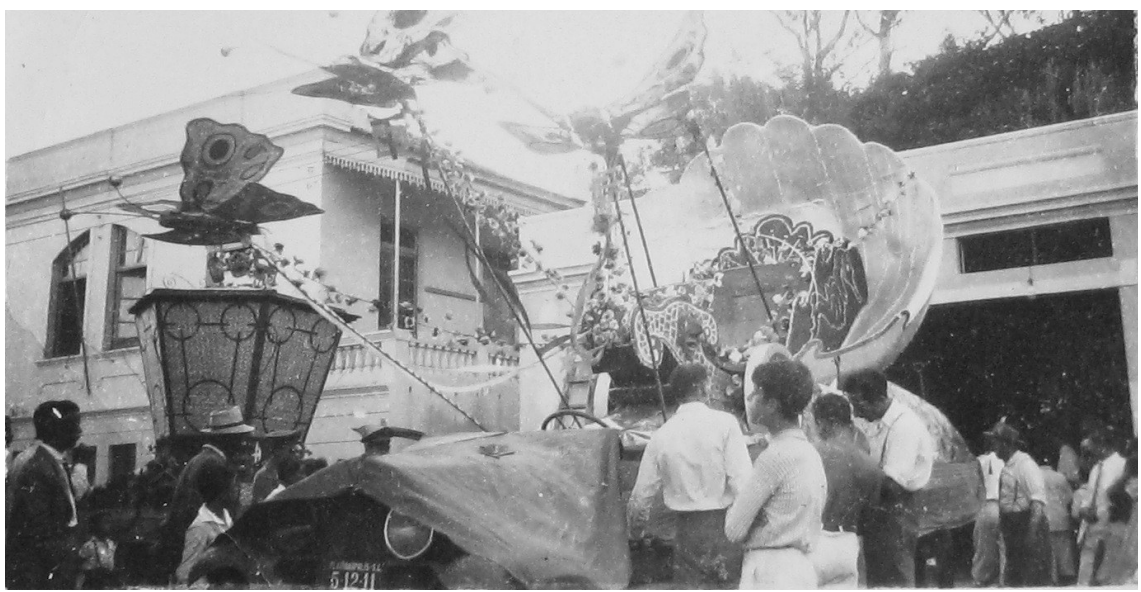

Figura 2: Carro de mutação criado por Acary Margarida; carnaval de Florianópolis, década de 1940 Fonte: coleção de fotos da família da artista

São estas as principais sociedades carnavalescas que existiram em Florianópolis no século XX: Granadeiros da Ilha, Tenentes do Diabo, Trevo de Ouro e Limoeiro. A Granadeiros da Ilha, que se originou da Filhos da Minerva, foi fundada em 1949 e teve o jornalista Jairo Calado como primeiro presidente. A Tenentes do Diabo, também criada em 1949, pertencia à família Gevaerd. A Sociedade Carnavalesca Trevo de Ouro, antiga Vai ou Racha, data de fevereiro de 1969, sendo Acary Margarida um de seus fundadores, e, mais tarde, seu filho Lauro Margarida presidente. Já a Limoeiro, do bairro do Saco dos Limões, a mais tardia delas (1978), pôde beneficiar-se de novas tecnologias e passou a inovar nos efeitos especiais e na decoração de seus carros.

Resultado do trabalho criativo e minuciosamente artesanal de um grupo de pessoas abnegadas, cuja única gratificação é ver a multicoloridade feérica dos carros encantar o povo nas noites de carnaval, as Grandes Sociedades, nestes 30 anos, transformaram-se num espetáculo sem paralelo no carnaval brasileiro. Isso porque suas mutações são as únicas no país (RAMOs, 1997, p. 44).

Os carros de mutação foram grande diferencial no carnaval de Florianópolis, marco que ficou na memória de muitos habitantes. Acary Margarida atuou na produção de carros alegóricos e de mutação para sociedades carnavalescas de Florianópolis e, também, de outras cidades do Estado de Santa Catarina, como Blumenau, Itajaí e Videira, levando mão de obra e tecnologia dos carros de mutação, que eram exclusivas do carnaval ilhéu (figuras 2 a 4). 

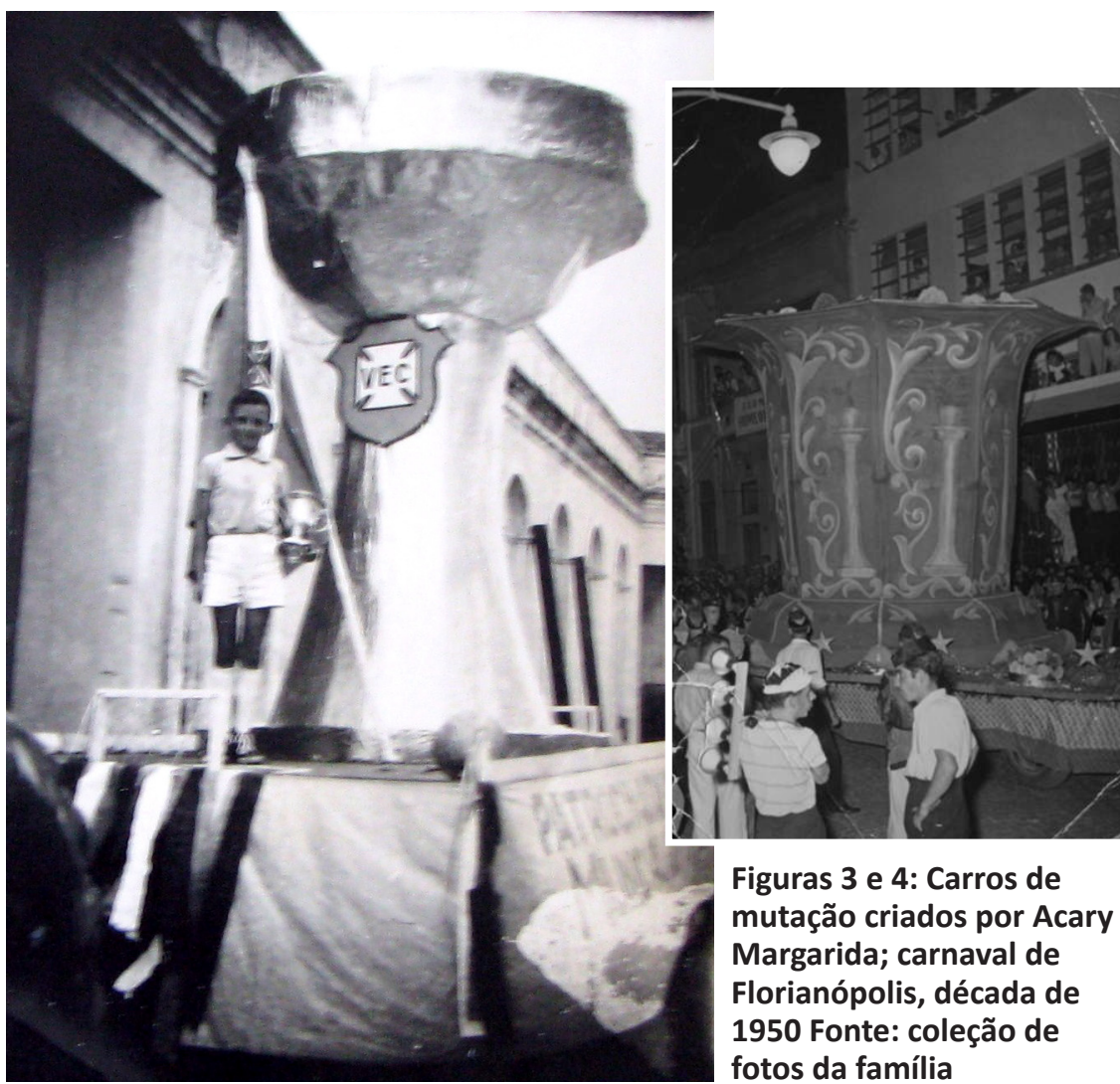

Figuras 3 e 4: Carros de mutação criados por Acary Margarida; carnaval de Florianópolis, década de 1950 Fonte: coleção de fotos da família

A montagem dos carros exigia muita habilidade técnica, segundo Acary Francisco Margarida, ${ }^{4}$ neto de Acary Margarida, "uma combinação de mãos leves de artistas com braços fortes de operários". Um tablado era montado sobre um chassi de caminhão, formando uma espécie de carretão decorado, sobre o qual eram colocadas as alegorias e mutações. A engrenagem que permitia as mutações era instalada embaixo do carretão. Na parte da frente, instalava-se um cambão engatado para ser puxado por tratores, jipes ou caminhonetes. O sistema era formado por catracas manuais com roldanas e acionado por manivelas, proporcionado o movimento das figuras decoradas. Muitas vezes os carros quebravam durante o desfile e tinham que ser movidos pela equipe de apoio. A criatividade dos carnavalescos responsáveis pela criação das peças passeava entre castelos, dragões, aviões, navios, bruxas e animais lendários pertencentes ao folclore local, como se pode observar nas figuras 5, 6 e 7, que apresentam carros de mutação da Sociedade Carnavalesca Granadeiros da Ilha, no carnaval de Florianópolis, na década de 1950. 


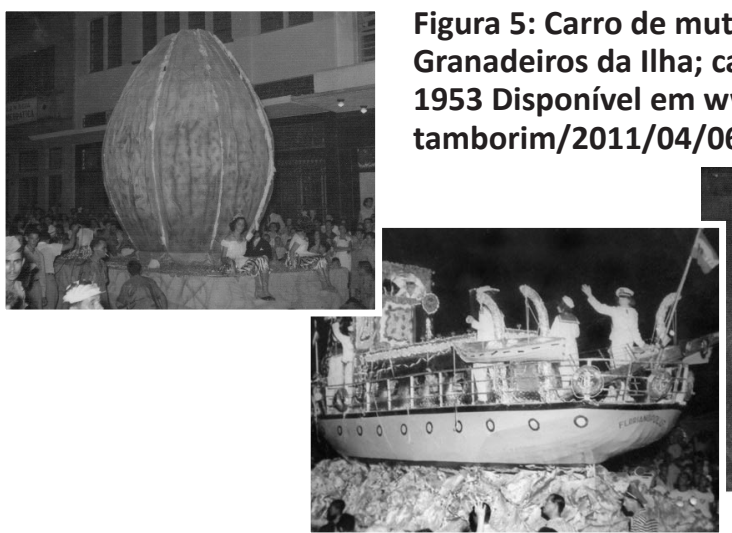

Figura 7: Carro de mutação "Navio", da sociedade Granadeiros da Ilha; carnaval de Florianópolis, 1958 Disponível em www.clicrbs.com.br/ tamborim/2009/06/11

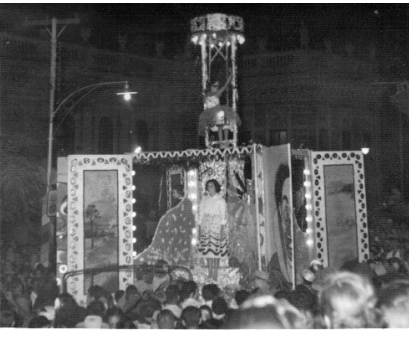

Figura 6: Carro de mutação "Quatro Estações", da sociedade Granadeiros da Ilha; carnaval de Florianópolis, 1954 Disponível em www.clicrbs.com.br/ tamborim/2011/04/06

Os barracões das grandes sociedades funcionavam praticamente todo $\mathrm{o}$ ano e eram grandes oficinas profissionalizantes. Em todas elas, as crianças acompanhavam o trabalho de marceneiros, carpinteiros, serralheiros, pintores e de artistas em geral, funções que, com frequência, mais tarde vinham a desempenhar. Fazia-se uso de material reciclado, como sucatas, tampas de garrafa, maços de cigarro e plástico como matéria-prima para o trabalho artístico. Segundo Cavalcanti (1999), a produção das alegorias carnavalescas faz parte de uma arte coletiva, pois, sendo elas concebidas pelo carnavalesco, seu processo de criação possui um objetivo comum em torno do qual se reúne uma equipe de especialistas com seus ajudantes. A relevância das alegorias carnavalescas deve ser atribuída a sua força artística e significativa, correspondendo a uma forma de expressão carnavalesca para mostrar ao público, através da alegria e também da crítica, as transformações de seu tempo.

As alegorias carnavalescas trazem consigo esse sentimento do mundo. Para além do tópico do enredo que ilustram, lançam mão de uma infinidade de elementos que retém simultaneamente a muitos e imprevistos significados. As alegorias carnavalescas dizem uma coisa, significam muitas, num jogo livre de alusões. Exaltam ironicamente objetos banais e corriqueiros, que ganham dimensões monumentais. Misturam elementos aparentemente descon- 
exos. Brincam com a ambiguidade, intrigam, surpreendem. Uma vez prontas para serem apreciadas, parecem inesgotáveis, e, no entanto, logo acabam (CAVALCANTI, 1999, p. 50).

A história das grandes sociedades carnavalescas está intimamente ligada à história de determinadas famílias de carnavalescos da cidade. Os precursores foram Acary Margarida, cujo legado foi mantido pelos filhos e netos até 1988, Davi Gevaerd, João dos Passos Xavier, Franklin Cascaes e João Cheiroso. $\mathrm{O}$ carnavalesco Nilson Nelson Machado ${ }^{5}$ argumenta que as grandes sociedades carnavalescas ficaram sem apoio oficial e sem parceria com as escolas de samba. $O$ desaparecimento dos patriarcas dessas famílias também contribuiu para a extinção das sociedades. $O$ último desfile das grandes sociedades aconteceu em 1988. Após longo período fora do carnaval, em 2007, as sociedades carnavalescas Tenentes do Diabo e Granadeiros da Ilha voltaram a desfilar, recebendo subvenção para resgate cultural, uma parceria entre patrocínio privado e ajuda do Estado. Rodrigo Leifer, atual presidente da Tenentes do Diabo, esclarece as diferenças entre o trabalho de um carro de mutação e de um alegórico, "na escola de samba o forte é ferragem. Nós aqui usamos a madeira, o papel, o grude, as caixas e manivelas". ${ }^{6}$ Os dois tipos de agremiação dividem em harmonia o mesmo espaço de trabalho, pois não existem mais disputas por concurso e premiação. $\mathrm{O}$ objetivo do ressurgimento das antigas sociedades carnavalescas é resgatar um passado rico em criatividade e ousadia e manter viva a tradição.

Quando se propõe rever o espaço ocupado por certos tipos de objetos que foram encobertos por preconceitos e rejeitados, pretende-se pensar a contribuição que eles podem trazer para a renovação da escrita da história da arte. A pesquisa e o estudo da produção artística voltada para o carnaval revelam importante contribuição para essa nova maneira de pensar e escrever a história da arte, rompendo antigos padrões e revendo conceitos. Voltar a atenção para os objetos alegóricos pertencentes ao carnaval permite acessar novos territórios, além de "repensar certos estatutos de verdade sobre as obras de arte, sobre o valor das instituições no balizamento dos discursos de competência e a importância dos lugares ocupados pelos objetos no julgamento de qualidade de uma obra" (MALTA, 2009, p. 2375). Os objetos alegóricos, mais especificamente os carros de mutação, com sua manufatura específica e exclusiva, fornecem subsídios suficientes para ocupar lugar de destaque nesse novo olhar sobre a história da arte. 


\section{REFERÊNCIAS BIBLIOGRÁFICAS}

CAVALCANTI, Maria Laura V. O rito e o tempo: ensaios sobre o carnaval. Rio de Janeiro: Civilização Brasileira, 1999.

COLAÇO, Thais L. O carnaval no Desterro: século XIX. Dissertação em História. Florianópolis: UFSC, 1998.

MALTA, Marize. O caso de uma obra sem lugar e a discussão sobre o lugar da obra de arte decorativa. Anais do $18^{\circ}$ Encontro da Associação Nacional de Pesquisadores em Artes Plásticas -“Transversalidades”, Salvador, BA, 2009.

. Casa Assombrada ou Circo dos Horrores? Discussão sobre territórios para objetos do mal. Anais do 19 Encontro da Associação Nacional de Pesquisadores em Artes Plásticas - "Entre Territórios", Cachoeira, BA, 2010.

RAMOS, Atila Alcides. Carnaval da Ilha. Florianópolis: Papa Livros, 1997.

VINHOSA, Luciano. Práticas artísticas de fronteira: alguns tópicos para reflexão. 2011. Publicação digital. Museu de Arte Moderna do Rio de Janeiro. Disponível em http://seminario.mamrio.org.br. Acesso em 19.3.2012.

\section{NOTAS}

1 Luciano Vinhosa, professor do Departamento de Arte da UFF (RJ), no artigo "Práticas artísticas de fronteira: alguns tópicos para reflexão" aborda a questão do alargamento das fronteiras do fazer artístico a partir dos campos híbridos de atuação do artista, do educador e dos agentes sociais.

20 pai de Acary Margarida, Joaquim Margarida foi professor de desenho, caligrafia e geometria no Liceu de Artes e Ofícios, e ilustrador do periódico crítico A Matraca. Seu avô paterno, Alexandre das Oliveiras Margarida, foi um dos fundadores do Liceu de Artes e Ofícios, onde também foi professor de litografia, tipografia e encadernação.

3 Nota veiculada no jornal O Estado, em 26.2.1949, sobre os preparativos para o carnaval daquele ano.

4 Entrevista concedida ao Jornal ANcapital em 2.3.2003, reportagem de Edson Rosa. Disponível em http://www1.an.com.br/2003/mar/02/1ult.htm. Acesso em mar.2012.

5 Entrevista concedida ao Jornal ANcapital em 2.3.2003, reportagem de Edson Rosa.

6 Entrevista concedida a Ângela Bastos publicada no jornal Hora de Santa Catarina em 31.1.2011. Disponível em <http://www.horasc.com.br/tamborim>. Acesso em mar.2012.

Fabiana Machado Didoné é bacharel em artes visuais pela Universidade do Estado de Santa Catarina - Udesc e mestranda do Programa de Pós-Graduação em Artes Visuais Udesc. 